\title{
Teaching the "How" of Engineering Innovation
}

\section{William R. Cockayne, John M. Feland III, Larry Leifer Center for Design Research, Stanford University}

\begin{abstract}
Innovative capacity is a function of 'knowledge how', not 'knowledge what'.
\end{abstract}

In order to create greater value for society, the engineer of the $21^{\text {st }}$ Century needs to build on the traditional content-driven education by becoming fluent in multiple disciplines. Drawing on expertise from multiple fields will enable today's engineer to become society's cultivator and harvester of innovations. This pandisciplinary approach is critical in identifying and defining innovative solutions, which are historically discovered at the intersection of disciplines. The "pangineer" - or pandisciplinary engineer - is already at work in the field of smart product design, which integrates a range of disciplines including electronics, mechanics, product design and software. Moreover, the panengineer is leading society in the discovery and application of next generation biotechnology, nanotechnology and alternative energy products.

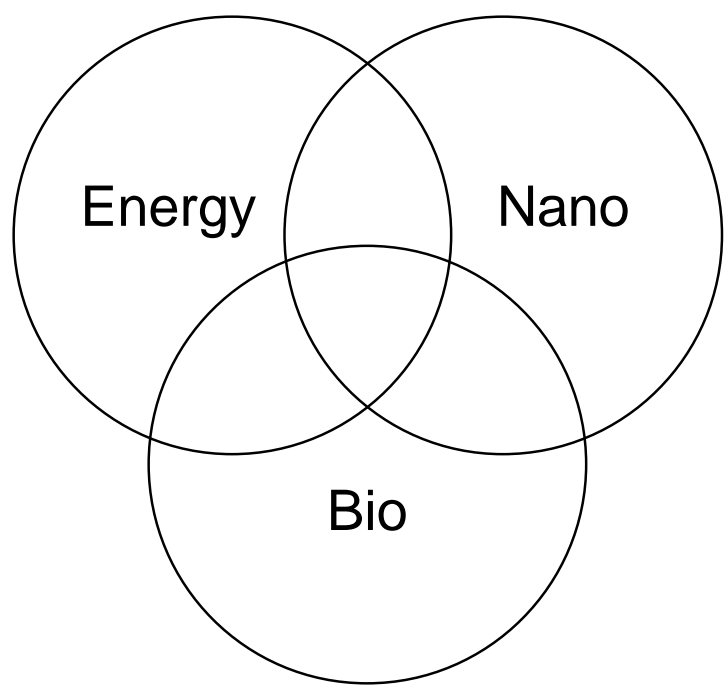

Figure 1. Interdisciplinary Innovation - The greatest innovations occur at the intersection of domains.

Any discussion of the pangineer must begin with the current education of engineers. Traditional engineering education has typically presented content knowledge across multiple disciplines; however, to prepare students for modern challenges, the modern education system must now focus on delivering the context across and between the these content areas.

Knowledge how, or know-how, has always existed in engineering learning and practice. A common example recalled fondly by today's practicing engineers are project-based classes, such as capstone design courses for Mechanical Design engineers. Such classes

Proceedings of the 2002 American Society for Engineering Education Annual Conference \& Exposition Copyright $@$ 2002, American Society for Engineering Education 
attempt to integrate content knowledge "silos" of mechanics, design, materials, etc., along with cross disciplinary skills in conceptualization, knowledge capture, writing and presentation. The industry is increasingly demanding students with learned know-how students that possess the ability to understand multiple content areas as well as demonstrate experience with applied problem solving.

The demand for engineers with business knowledge, driven in part by the growth of management consulting firms, has led to numerous programs in entrepreneurship in academia. But the lack of integrated context knowledge, know-how, may limit the effectiveness of these early programs.

The pervasiveness of learning-by-doing curriculum is driving the need to educate engineering students in their future role as knowledge holders, creators, team members, builders and, ultimately as, innovators. This paper hopes to continue the development of these curricula by presenting know-how as an intentioned framework.

\section{KNOW-HOW}

Know-how is not a new concept. Aristotle (384-332 BCE) was one of the earliest thinkers to make a distinction between know-what - content knowledge or disciplines and know-how - the oftentimes-messy aspects of self-awareness and applied teamwork. In Metaphysics, Aristotle speaks of episteme as abstract generalizations and scientific laws or principles. This type of content has been traditionally taught to engineering students, often providing each student's core set of beliefs toward reality. According to Aristotle, techne -- or technical know-how -- is "information that is not captured well in manuals, and the 'in-between' knowledge that exists in communities of practice." 2 Since Aristotle's wisdom, modern education has often overlooked this meta-level of content.

Today, The Economist reports that Eastern Europe is experiencing a revolution in higher education, looking to lose the traditional path of teaching know-what by focusing on know-how. These students have begun to "shell out their own money to go to private, tuition-financed colleges and universities" as "far more people, sensing opportunities under capitalism, were suddenly avid for the know-how to push themselves forward." 3

Leading knowledge-management companies are also reintroducing and, more importantly, espousing know-how. Recently, IBM Systems Journal stated:

The organizational knowledge that constitutes "core competency" is more than "know-what," explicit knowledge which may be shared by several. A core competency requires the more elusive "know-how" - the particular ability to put know-what into practice. ... Know-how [is] embedded in work practice (usually collective work practice) is sui generis and... can be hard to spread, coordinate, benchmark, or change. ${ }^{4}$

While the general definition of know-how has remained consistent through time, the nuances across society, university and industry are loose approximations. The first step in communicating within and across different groups is a common language. At present, there is no commonly accepted framework related to the "how" of engineering

Proceedings of the 2002 American Society for Engineering Education Annual Conference \& Exposition Copyright () 2002, American Society for Engineering Education 
innovation. By adopting a framework, engineering educators and researchers will be able to credibly compare research methods, results, definitions, requirements, methods and tools as well as develop learning paths, performance metrics and, later, standards for individuals, teams and professional organizations. Ultimately, both engineering researchers and practitioners will use this framework to clearly communicate with one another and under gird their work with innovative systems, methods and tools.

This paper discusses fundamental areas of know-how that include self-awareness, group understanding and common languages - all factors that engender trust within social networks. Each area defines the primary problem, provides a brief set of early solutions, and then describes possible tools for duplication or extension at other universities. However, this paper presents only a subset within a greater framework of engineering know-how, an area of study that remains available for further definition and illumination.

\section{AREAS OF KNOW-HOW}

British historian James Burke spoke about a "web of knowledge" that emerges from group interaction during innovation development:

Innovation is often surprising and unexpected because the process by which new ideas emerge is serendipitous and interactive.... Interlocking threads of ideas, people and events are woven into a web of knowledge and - bingo - we get today's world of science and technology.

All methods and tools described within require interactions between individuals. These interactions prompt individuals to share beliefs, goals and multiple types of knowledge that, when combined, build a common trust and shared experience within the group. This interaction also provides the foundation for a common context - or, know-how - that enables innovative breakthroughs.

Self-awareness \& group understanding. In the last decade, engineering programs across the U.S. have gradually shifted their focus from teaching skill-and-drill to the lone-engineer to teaching applied problem solving for teams. The intention of this approach is to create an awareness in students about their skills, preferences and personalities. Self-awareness is then carried into a team-based environment where it can be shared and built on. Independent of any measurable increase in team output or quality, students going through this process often relate that a better team, project and learning experience occurs.

One common set of tools for self-awareness is the Myers-Briggs Type Indicator (MBTI) and Keirsey Temperament Sorter. This popular personality tool is usually completed before the first day of class and then shared by the students, as much as an icebreaker as an educational or team-building tool. Little is usually done with the results of the tests in actual team creation beyond anecdotal rules about complementary personalities as an indicator of team success. Another tool in this vein is the enneagram, which again has a goal of self-awareness and little else. Recent work in this area has been the use of Jungian archetypes to create personal maps, which are then explicitly used to create team maps, aiming for the creation of healthier and better performing teams. Dr. Doug Wilde of Stanford University has been working for over a decade to combine and extend the

Proceedings of the 2002 American Society for Engineering Education Annual Conference \& Exposition Copyright (C) 2002, American Society for Engineering Education 
MBTI and Jungian personality theory to the understanding of individuals and creation of engineering teams. ${ }^{5,6}$ This work has been applied within the Stanford Mechanical Engineering graduate design program to form design teams and increase student awareness within the context of team activity. Team performance and satisfaction have shown a marked performance increase in many of the years that Wilde's methods have been used. Wilde's methods currently require a high level of mathematical sophistication to use, which has created a high barrier for the wider use of his methods.

Another approach to providing engineers and engineering students with self-awareness is via lists of technical and personality skills. Such a system often comprises a list of 20 to 200 skills with corresponding columns for the student to select level of expertise. These systems, like most categorization tools, can be "graded" by the individual or by an outside group of peers. Results can be used to design new learning experiences or career goals; capture and compare previous experiences; or create a new, shared language for communicating among individuals who have used the system. A good example from the field of engineering product design is IDSA's Industrial Design Evaluation for Technical and Personal Skills. ${ }^{7}$ In this system, forty-three technical skills are presented with expertise rating of Outstanding, Above Average, Good, Marginal, or Unsatisfactory. Examples of the technical skills are:

- analysis

- drafting

- implementation

- planning

- usability testing

- writing

One hundred and ten personal skills are first super-classed into ten areas - Intelligence, Interpersonal, Communications, Maturity, Energy, Financial, Entrepreneurial Sales, Management, Other, and Non-Design Pursuits - with ratings of Yes, No, Sometimes, or Often. Examples of personal skills are:

- flexible

- team player

- articulate

- cooperative

- vigor

- set budgets

- builds relationships

- prioritizes clearly

- publishes

While the IDSA tool is a valuable start, it lacks much of the rigor that can be seen in refined taxonomic classifications. Some of the issues that should be addressed would be the inclusion of examples for the definitions, many of which are clearly not separable, and the explanation of assumptions made during the development of the lists.

We have used taxonomic methods to create the Engineering Content Skills Matrix (ECSM), which presents both skills and content areas. The ECSM was developed as a 
tool to create self- and group-awareness across disciplines and skill sets. This Matrix provides an understanding of content and skills - coupled know-how - for students choosing classes; building degrees; choosing and defining a career; and for creating continuous learning and career development goals.

SAMPLE

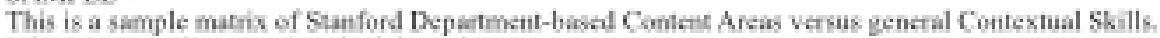

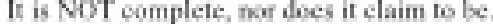

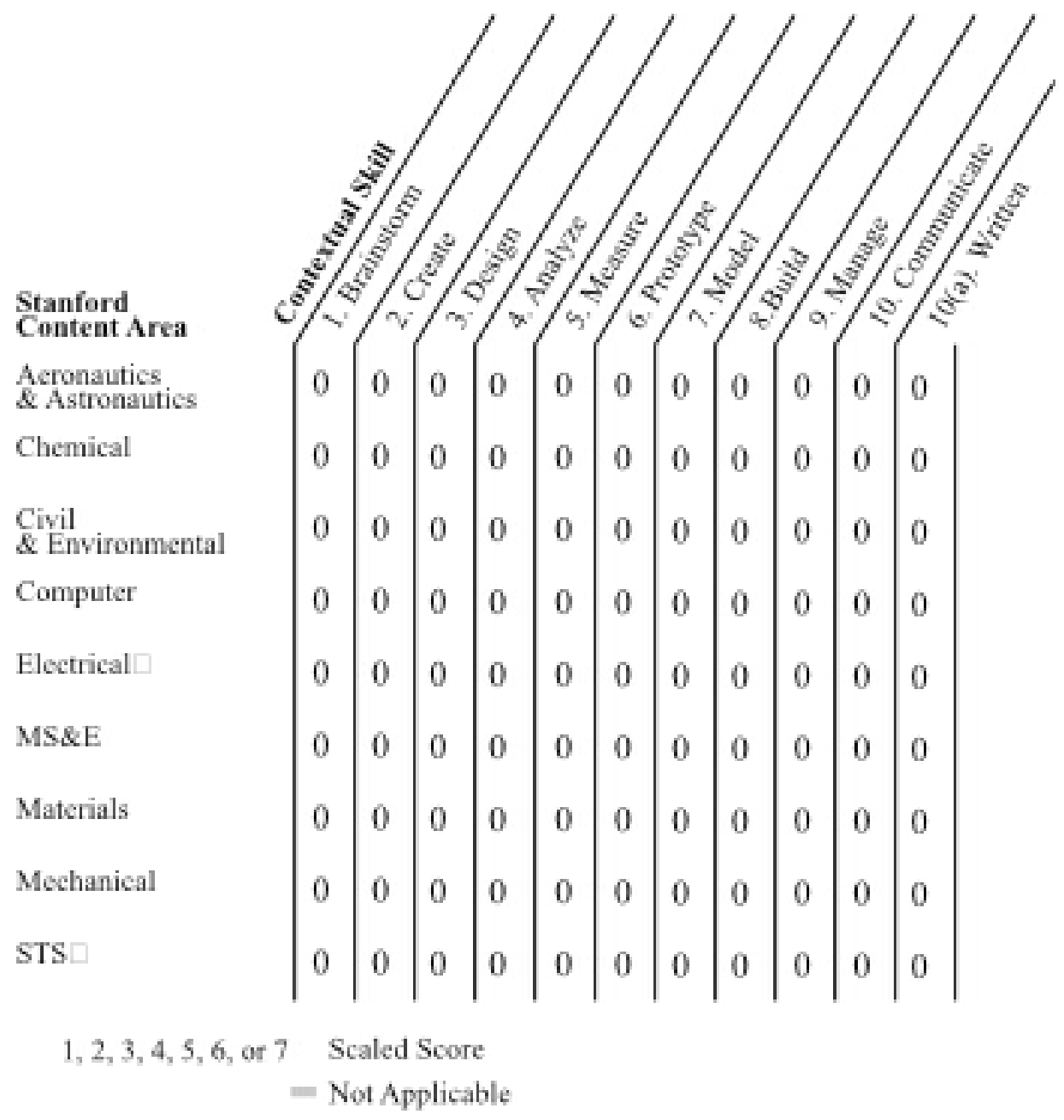

Figure 2. Engineering Matrix. The presence of a Skill within a Content area is presented defined quantitatively, or can be used for simply communicating presence.

To effectively achieve understanding and communication in use, this tool was designed to be simple. The presentation of the tool is in a standard two-dimensional matrix, with content areas down the left side and skill areas along the top. In the field of engineering, content areas often develop into fields of practice or departments. This assumption allowed us to map the content areas to standard engineering departments, which can then be sub-classed, if needed. At Stanford University, for example, the left-hand column contains the names of the eight departments: Civil, Mechanical, Management Science \& Proceedings of the 2002 American Society for Engineering Education Annual Conference \& Exposition 
Engineering, et al. As an example of sub-classing, each of Stanford's departments comprises multiple, non-overlapping content areas, which can be included when the discussion requires. An example of this would be the Management Science \& Engineering department, which is the result of three mergers. The four original content areas are still used for discussions internal to the department, but rarely by outside students. The content list can also be extended easily as new fields are defined, which has been recently occurring at Stanford University through the creation of a Bioengineering department, comprised of new classes and research areas.

The columns relate to skills that transcend any particular content area. The technical and personal skills that are defined by IDSA are very similar to the above matrix, although we have strived to provide conceptually separable terms. We are presently continuing the creation of definitions and examples for each of the skills, which will be provided along with the matrix. By moving across a content area, column-by-column, a student or practicing engineer can choose which skills he possesses in that discipline. The scoring can be straight absence/presence, groupings like those used in the IDSA system, or some form of quantitative score, such as years of experience. Because we have designed the skills to progress from left to right in some relation to the development of an actual engineer's skills, a student can begin to understand their educational path as they begin to populate the left-hand side of the matrix. Students can also begin to understand how the development of a skill, such as analysis, can be used to engage a new content area by moving down a column. The use of the matrix helps students to:

- Understand and track the skills that will be learned during their education and throughout a career;

- Understand the skills that are required for a class or the skills that a class hopes to deliver;

- Compare their skills and content with other students, standard curricula, degrees at other institutions, or with engineering careers that they are interested in.

- Speak with other engineers, possibly as part of a team, academics, researchers, or practitioners about their background and goals.

Shared models and languages. The rapid increase in content skills required to solve real world problems is bringing together diverse groups of academics, practitioners and students. Each of these individuals and groups brings a set of methods and language that is used in their field. A critical issue in the creation, maintenance and advancement of know-how is the concept of codifiability. As with any field of new or advancing knowledge, the problem of finding a language on which to construct a useful dialogue is a precursor to codifiability. In such situations, the development or adoption of a common language becomes the framework for further creating, capturing and sharing of new products and processes. Aristotle's knowledge types, MBTI and the Engineering Content Skills Matrix are all common languages. A common language - such as taxonomic classifications, models, metaphors, and even stories - provide an ability to generalize across events, an important goal of science, and for establishing and enhancing communication among participants. 
We have begun the development of a common language for the support of interaction as a driver of innovation processes. We intend for this language to act as an initial framework to support the creation and sharing of concepts, definitions, and languages among individuals and groups. While innovation is non-deterministic, our models are designed to create intention on the part of individuals and support the underlying traits of continuous innovation. Our framework is built from a small set of models and terms that do not aim to be exclusionary or final. The framework is designed to further education and to create a continuing dialogue among students, academics and practitioners.

One of the first models that we use supports high-value communication during team formation and the early stages of product or process conceptualization. The tool helps students to share their beliefs, goals and hopes for a project, for the team and for themselves. The tool then supports the individual or team in transitioning the project from conceptualization to design and implementation. This tool is based on a creativity process model developed by Matt Taylor during twenty years of work with corporate and government teams. Matt created the original model for use in a multi-day, facilitated, event-based environment that was designed to produce "GroupGenius.",

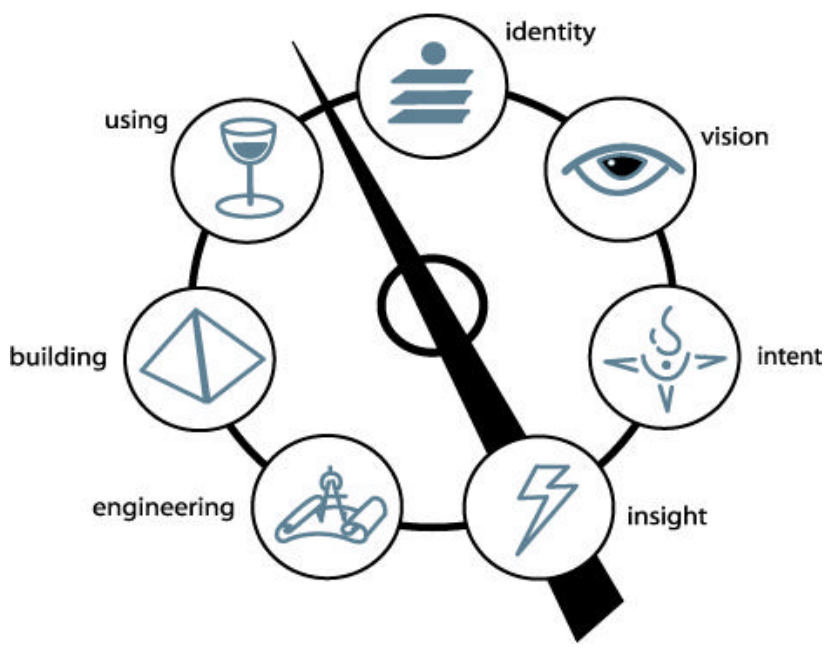

Figure 3. Creativity Model. This model presents a process for creation of new products or processes.

We have primarily adopted the visual element of the model and the first level terminology - vision, intent, and insight, et al. - while choosing to ignore the multiple levels of recursion in the language and model, the specialized definitions developed for each word, and the deep meanings associated with the custom glyphs for each stage. While these latter features of the model are not incorrect, we have chosen not to use them in the class or project setting. While we have simplified this and other models, we will not deny that the extensive work and thinking that went into their work has influenced our discussions.

Focusing again on the model, individuals and groups can use it to capture the early interaction that defines brainstorming, conceptualization and invention. Once captured, the students can revisit these codified interactions in later stages of the project or team development. The model usage additionally supports lessons on the importance and 
language, capturing tacitness, sharing, and value of a project framework. The model is also usable within networked communities of engineers in order to foster an innovation habitat, focusing again on creating, capturing and sharing know-how along with content knowledge - moving a large step beyond much of today's knowledge management systems. ${ }^{9}$ Finally, the model supports:

- A conceptual understanding of iteration, "all design is redesign," and unlearning/relearning that exists throughout a project's life,

- The cultural change that occurs as models move from being new to full adoption; and

- The use of a simple model to support individuals and groups as problems become increasingly complex.

A second model educates students to the existence, creation and management of social networks of innovation. Recent interest in this topic has been supported by a glut of academic and occupational books discussing social networks in Silicon Valley, with Stanford University as a key player across booms and disciplines. ${ }^{10}$ In teaching social networks, the first barrier today is in understanding the existence and use of such networks by engineers. While practicing engineers are often members of multiple professional organizations such as IEEE, ASME or ASEE, these groups do not necessarily act as social networks, in an operant sense, although subgroups or committees may provide this function.

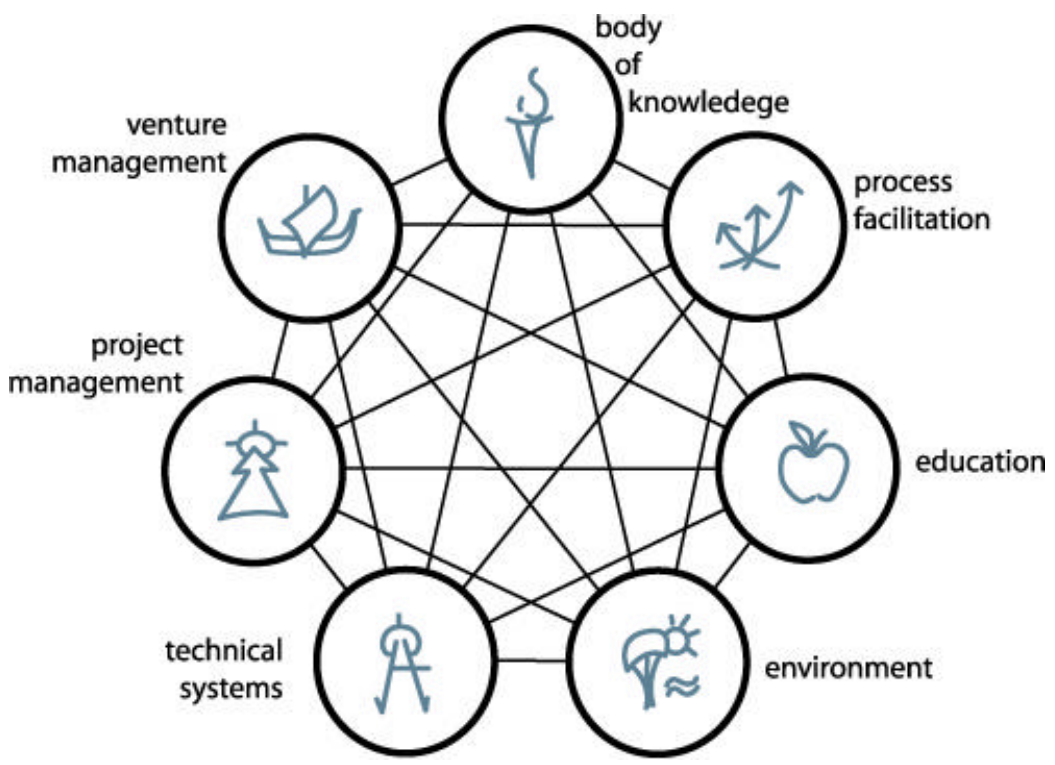

Figure 4. Social Network Model. The Seven Domains model presents areas where social network partners exist.

We again adopted the visual and first-level language elements for this model from work done by MGTaylor. In this instance we are actually using the model in a different way than that of MGTaylor. This model is presented with a concept of social networks 
developed by Janine Nahapiet at Oxford University and Sumantra Ghoshal at the London Business School. They view social capital as:

$[T]$ he sum of the actual and potential resources embedded within, available through, and derived from the network of relationships possessed by an individual or social unit [in which] there must be a series of connections that individuals have to others. In other words, individuals must perceive themselves to be part of a network (the structural dimension). A sense of trust must be developed across these connections (one aspect of the relational dimension). ${ }^{11}$

The individual, group or other units are defined by the circles in the visual, with the seven circles roughly associating with major roles in a project. The lines between the circles describe the relationships, connections or trust - much of the know-how - that underlies a social network. Students use the model to begin mapping their personal social networks, along with other values for the interconnections between the nodes, before moving on to the group and project networks. This model is also used to explain the concept of social innovation where the agents create a situation where they are highly coupled in their beliefs, goals and language, while remaining loosely coupled in terms of finances and schedules. As students become accustomed to maintaining the health of their social networks they can:

- Begin to operate more efficiently within the network, further extending or strengthening the network itself,

- Draw on the extended body of content knowledge and know-how that exists in and between nodes,

- Tap the connections and resources of the network agents, and

- Begin to think and perform as nodes in a networked, innovation habitat.

\section{CONCLUSIONS}

Engineering education is bolstering its traditional strength in content knowledge, or know-what, by intentionally teaching know-how. This trend began in the late twentieth century with the creation of project-based learning programs at leading universities, allowing engineering education to adopt traditional learning-by-doing methods from apprenticeships, the crafts industry and advanced graduate education. With these methods accepted, the need has now moved to understanding aspects of learning-bydoing and developing explicit topics, models and tools. This paper reviewed several tools for creating self-awareness and group understanding; shared beliefs, goals and languages; and social networks. The creation and use of these tools are already in use at leading universities, with the expectation that they will spread throughout the educational system over the coming decade. Along with their use in engineering education, we are already seeing interest in the topics, models and tools from industries and other education areas. Now more than ever, engineering students need to be prepared for radical changes in every existing discipline along with the creation of areas of learning and application that are unimagined today. By pursuing a pandisciplinary approach, today's engineer will be suitably prepared to create, develop and anticipate the world's next set of 
innovations. Education can set the pace for this development - providing the curriculum, tools and frameworks that continue integrating know-how with know-what.

\footnotetext{
${ }^{1}$ Cowan, R., David, P. and Foray, D., 1999, “The Explicit Economics of Knowledge Codification and Tacitness," Stanford University, Department of Economics Working Papers 99027.

2 Baumard, P., “Oblique Knowledge: The Clandestine Work of Organizations," Cahier de recherche DMSP, $\mathrm{n}^{\circ} 228$, Université de Paris-Dauphine, 994.

3 "Less of the state, please - Private education in Central Europe," The Economist, January 5, 2002.

${ }^{4}$ Brown, J.S. and Duguid, P., “Organizing Knowledge," California Management Review, Spring, Vol. 40, No. 3, pp. 90-111, 1998.

${ }^{5}$ Wilde, D., "Changes Among ASEE Creativity Workshop Participants," Journal of Engineering Education, 82, 3, July 1993.

${ }^{6}$ Wilde, D., "Mathematical Resolution of MBTI Data into Personality Type Components," American Society of Mechanical Engineers 1993 Conference on Design Theory and Methodology, Albuquerque, NM, September 1993.

${ }^{7}$ Seigel, R., Getting an Industrial Design Job - Special Report, originally published in IDSA Innovations.

${ }^{8}$ Peterson, C., Leaping the Abyss: Putting Group Genius to Work, based on the work of MGTaylor, knOwhere Press, 1997.

${ }^{9}$ Thomas, J., Kellogg, W., and Erickson, T., "The knowledge management puzzle: Human and social factors in knowledge management," IBM Systems Journal Vol. 40, No. 4, 2001.

${ }^{10}$ Next Silicon Valley Group of Joint Venture: Silicon Valley Network, "Next Silicon Valley: Riding the Waves of Innovation," December 2001.

${ }^{11}$ Nahapiet, J. and Ghoshal, S., "Social Capital, Intellectual Capital and the Organizational Advantage," Academy of Management Review 23, No. 2, 242-266, 1998.
}

WILLIAM R. COCKAYNE is a Research Associate at the Stanford Center for Design Research. He has held multiple industry research and development positions with Eastman Kodak, DaimlerBenz Research, Apple Computer and the U.S. Navy. He returned to Stanford to complete his PhD after spending two years developing a consumer wireless product as the cto and co-founder of Scout Electromedia.

JOHN M. FELAND III is a Research Associate at the Stanford Center for Design Research. A former Assistant Professor of Engineering Mechanics at the U.S. Air Force Academy, he returned to Stanford to finish a PhD. He has published in the areas of design education and knowledge capture, systems engineering requirement creation, innovation and entrepreneurship education, and team building.

LARRY LEIFER is a Professor of Mechanical Engineering and the Director of the Stanford Center for Design Research. He has published in the areas of diagnostic electrophysiology, human operator information processing, design team protocol analysis, design knowledge capture and concurrent engineering. A faculty member since 1976, he has taught Smart Product, Team and Mechatronic Design. 